\title{
Validation of the Core Beliefs Inventory (CBI) in Brazilian Portuguese
}

\author{
Validação do Core Beliefs Inventory (CBI) em português do Brasil
}

Tayse Conter de Moura, ${ }^{1,2}$ (D) Julia Candia Donat, ${ }^{1,2}$ Thiago Loreto Garcia da Silva, ${ }^{1,2}$ Adriane Xavier Arteche, ${ }^{1,2}$ Carolina Saraiva de Macedo Lisboa, ${ }^{1}$ Christian Haag Kristensen ${ }^{1,2}$

\begin{abstract}
Introduction: Experiencingtraumamayentailpsychopathological consequences, but also changes considered to be positive (i.e., posttraumatic growth). For positive change to occur, an impact on the beliefs of individuals is required, which may be measured through the Core Beliefs Inventory (CBI). The objective of this study was to validate the Brazilian Portuguese version of the CBI.

Methods: A total of 248 university students $(65.7 \%$ female) answered the following assessment instruments: sociodemographic data sheet, Posttraumatic Growth Inventory (PTGI), Posttraumatic Symptoms Checklist - Clinician Version (PCL-5) and the CBI. Psychometric properties of the CBI were assessed by conducting an exploratory factor analysis through a principal component analysis with varimax rotation. Internal consistency (Cronbach's a) and convergent validity (Pearson correlation between instruments) were also investigated.

Results: The total scale showed adequate internal consistency $(a=0.83$ ). A single factor solution explained $42.63 \%$ of the variance of the CBI. Significant correlations were found between CBI and PTGI, and between CBI and PCL-5.

Conclusion: The psychometric properties indicated adequate internal consistency and construct validity of the Brazilian Portuguese version of the CBI.
\end{abstract}

Keywords: Posttraumatic stress disorder, posttraumatic growth, core beliefs, trauma

\section{Resumo}

Introdução: Experimentar um trauma pode levar a consequências psicopatológicas, mas também a alterações consideradas positivas (ou seja, crescimento pós-traumático). Para que mudanças positivas ocorram é necessário um impacto nas crenças dos indivíduos, o que pode ser medido através do Core Beliefs Inventory (CBI). O objetivo deste estudo foi validar a versão em português do Brasil do CBI.

Métodos: Um total de 248 universitários (65,7\% mulheres) responderam aos seguintes instrumentos de avaliação: ficha sociodemográfica, Inventário de Crescimento Pós-Traumático (Posttraumatic Growth Inventory - PTGI), Lista de Verificação de Sintomas Pós-Traumáticos - Versão Clínica (Posttraumatic Symptoms Checklist - Clinician Version - PCL-5) e CBI. As propriedades psicométricas do CBI foram avaliadas a partir de análise fatorial exploratória através de análise de componentes principais com rotação varimax. A consistência interna (a de Cronbach) e a validade convergente (correlação de Pearson entre os instrumentos) também foram investigadas.

Resultados: A escala total apresentou consistência interna adequada $(a=0,83)$. Uma solução de fator único explicou $42,63 \%$ da variação do CBI. Correlações significativas foram encontradas entre CBI e PTGI e entre CBI e PCL-5.

Conclusão: As propriedades psicométricas indicaram consistência interna adequada e validade de construto da versão em português do Brasil do CBI.

Descritores: Transtorno de estresse pós-traumático, crescimento pós-traumático, crenças centrais, trauma.

\footnotetext{
${ }_{1}^{1}$ Pontifícia Universidade Católica do Rio Grande do Sul (PUCRS), Porto Alegre, RS, Brazil. ${ }^{2}$ Núcleo de Estudos e Pesquisa em Trauma e Estresse (NEPTE), Porto Alegre, RS, Brazil.

Submitted Apr 25 2018, accepted for publication Apr 282019.

Suggested citation: de Moura TC, Donat JC, da Silva TLG, Arteche AX, Lisboa CSM, Kristensen CH. Validation of the Core Beliefs Inventory (CBI) in Brazilian Portuguese. Trends Psychiatry Psychother. 2019;41(4):409-414. http://dx.doi.org/10.1590/2237-6089-2018-0038
} 


\section{Introduction}

It is expected that 40 to $90 \%$ of the population will experience at least one potentially traumatic event during their lifetime. ${ }^{1}$ Surviving such events may result in different outcomes, the most cited in the literature being posttraumatic stress disorder (PTSD). ${ }^{2}$ PTSD prevalence in Brazil ranges from 7 to $11.7 \%$, indicating an important public health problem. ${ }^{3}$ However, most people seem to recover from traumatic events without developing symptoms or impairments, ${ }^{4,5}$ while others experience a positive outcome, such as posttraumatic growth. ${ }^{6}$

Posttraumatic growth is the perception of positive change experienced after a stressor, translating into improvements in interpersonal relationships, greater appreciation of life and redefinition of objectives and personal priorities. ${ }^{7}$ Evidence of posttraumatic growth exists in victims of sexual abuse, ${ }^{8}$ parents of children with terminal disease ${ }^{9}$ and cancer patients, ${ }^{10-12}$ among other populations. To our knowledge, there are no empirical studies investigating this phenomenon in the Brazilian population.

There is no consensus in the literature regarding how the processes underlying PTSD and posttraumatic growth interact. While several authors argue that posttraumatic growth results from PTSD, ${ }^{13-15}$ others believe that the processes coexist in a curvilinear relationship. ${ }^{16-20}$ Regarding the occurrence of posttraumatic growth, the type of traumatic experience is less relevant than the degree to which the individual reassesses beliefs about the world, self and others. These beliefs guide behaviors, help understand the causes of daily events and shape the development of a general sense of meaning and purpose. ${ }^{21}$ The discomfort raised by the conflict between previous beliefs and new and contradictory information is what leads individuals to generate more adaptive beliefs to a new reality, enabling them to acknowledge positive changes in their lives. ${ }^{21,22}$

Changes in beliefs following traumatic events are assessed through instruments such as the Posttraumatic Cognitions Inventory (PTCI), ${ }^{23,24}$ the Stress-Related Growth Scale, ${ }^{25}$ the Posttraumatic Maladaptive Beliefs Scale, ${ }^{26}$ and the Event-Related Rumination Inventory. ${ }^{27}$ However, none of these scales measures how intensely the event challenged an individual's beliefs, or which were the alterations in personal beliefs. To that end, Cann et al. ${ }^{21}$ developed the Core Beliefs Inventory (CBI).

The CBI is a self-report scale with nine items quantifying the degree to which beliefs about the self, world and others were "shaken" after a major event. ${ }^{21}$ Studies with the CBI corroborate the theoretical model of posttraumatic growth, displaying positive associations between degree of posttraumatic growth and how intensely participants reassessed their beliefs after the event, as well as between CBI scores and posttraumatic symptoms, although at lower levels. ${ }^{16,21,22}$ Replication of these results in different cultural contexts is important. ${ }^{28}$

A previous validation study of the $\mathrm{CBI}$ in the Portuguese language involving 456 Portuguese participants with a mean age of 34.87 (standard deviation [SD] = 12.52) indicated a mean of posttraumatic growth of $52.52(S D=24.42)$ and mean of $25.58(S D=9.36)$ in the CBI. ${ }^{29}$ To date, the psychometric properties of the Brazilian Portuguese version of the CBI were not investigated. It is crucial that robust, reliable and consistent assessment instruments are developed in posttraumatic growth research. Thus, the objective of this study was to investigate construct validity of the Brazilian Portuguese CBI.

\section{Method}

\section{Participants}

The sample consisted of 248 university students (65.7\% female, $\mathrm{n}=163$ ) with ages between 17 and 54 years (mean $=23.76, \mathrm{SD}=6.52$ ) from southern Brazil. Sample size calculations exceeded the criterion of Hair et al. ${ }^{30}$ of 5 to 20 observations per instrument item. Students were participating in a larger project that investigated the interaction of several variables of the posttraumatic growth phenomenon. Individuals who reported substance use disorders, psychotic disorders or neurological disorders were excluded from the study.

\section{Measures}

Sociodemographic data sheet

A questionnaire was developed by the research team to collect general information about participants, such as age, sex, education, medication intake, and socioeconomic status according to Brazilian Economic Classification Criteria. ${ }^{31}$ Questions about previous psychiatric history were also included to investigate exclusion criteria.

\section{Core Beliefs Inventory (CBI) 23,32}

This is a self-report instrument comprising nine questions about changes in beliefs following a specific traumatic event. The respondent is instructed to select the most striking and difficult event of his life and to consider the impact this event had on individual perception. For each question, the participant scores a Likert scale from 0 to 5 points, with 0 corresponding to "I did not experience this change," and 5 to "I have 
experienced this change to a great degree." The study describing the development of the $\mathrm{CBI}^{21}$ presents evidence of adequate internal consistency ( $a=0.82$ ) and reliability with the test-retest method $(r=0.69)$. A single dominant factor explained from 42 to $53 \%$ of the variance of the instrument.

\section{Posttraumatic Growth Inventory (PTGI) 7,32}

The PTGI is a self-report instrument with 21 items scored over a 5-point Likert scale that assess interpretations or positive changes that a stressor triggered in the individual, such as "I trust myself more" or "Now I know that I can deal with difficult situations." The original version comprises the following factors: New Possibilities, Relationship with Others, Personal Strength, Spiritual Change and Appreciation of Life. The development study ${ }^{7}$ reported adequate internal validity $(a=0.90)$ and reliability with the test-retest method $(r=0.71)$. The five factors explained $55 \%$ of the variance.

\section{Posttraumatic Symptoms Checklist - Clinician Version (PCL-5) 6,33}

This self-report instrument was used to obtain a diagnostic measure of PTSD. The scale comprises 21 items, one for each PTSD symptom listed in the Diagnostic and Statistical Manual of Mental Disorders, 5th edition (DSM-5). ${ }^{2}$ The respondent should inform whether in the last month he/she felt "none" up to "many" of a list symptoms such as "Feeling startled or easily frightened" or "Repeated and disturbing dreams concerning the traumatic experience." The scale provides a cutoff point ( 44 points) for the sum of scores obtained for all items.

\section{Procedures}

Translation and adaptation of the CBI into Brazilian Portuguese were carried out following a series of procedures that included translation, back-translation, expert committee's evaluation, and pilot testing in the target population (more details in Silva et al. ${ }^{32}$ ). After approval by the ethics committee, university students were invited to participate through posters placed around campus.

Data collection occurred at a clinical research facility of the university, always in individual sessions lasting 40 minutes on average. Participants were initially informed of the study objectives and asked to read and sign an informed consent term before the research procedures began. Then, they were instructed to select the most difficult situation that they had to cope with in their lives, and to answer the assessment scales according to their post-event reactions and symptoms. Participants who reported significant psychological distress (i.e., symptoms of depression, anxiety, or scores above the PCL-5 cutoff point) were referred to specialized clinical facilities. A follow-up session to discuss assessment results was offered to all participants. Those who requested the follow-up session scheduled an appointment with the psychologist in charge of the study.

\section{Data analysis}

Evidence of validity of the CBI was investigated in three stages: 1 ) exploratory factor analysis by principal component analysis using varimax orthogonal rotation; 2) analysis of the instrument's internal consistency via Cronbach's a; and 3) convergent validity analysis through Pearson correlation test among CBI, PCL-5 and PTGI scores. Data analysis was conducted in the Statistical Package for the Social Sciences (SPSS) version 17.0.

\section{Results}

The most recurrently cited stressful events were the death of someone close $(n=58 ; 23.4 \%)$ and family issues ( $n=48 ; 19.4 \%$ ), such as being expelled from home, parent divorce or suicide attempt of a family member. The mean score of the total CBI was 24.72 (SD $=10.07$ ). Table 1 shows mean and standard deviation values of additional measures applied in the study.

Cronbach's a $(a=0.83)$ indicated adequate internal consistency of the scale. The coefficients of the KaiserMeyer-Olkin (KMO) and Bartlett's sphericity tests were among the values recommended in the literature (KMO $\left.=0.83 ; \mathrm{X}_{36}^{2}=690.515 ; \mathrm{p}<0.001\right)$, indicating an adequate sample size. Diagonal elements of the antiimage matrix of correlations were above 0.7. These data indicate that factor analysis was possible and adequate. Furthermore, all items correlated adequately $(r<0.05)$, with no correlation coefficient greater than 0.9 . The issue of multicollinearity was not present, for the value of the determinant was 0.058 . Table 2 shows inter-item and item-total CBI score correlations.

Principal component analysis was conducted with varimax orthogonal rotation. A single factor solution (Eigenvalue $=3.83$ ) was found for all the items, explaining $42.63 \%$ of variance. Examination of factor loadings did not lead to item exclusions (all items > 0.40 ), as shown in Table 3. Convergent validity analysis relied on the associations between posttraumatic beliefs, posttraumatic growth and PTSD symptoms. Pearson's coefficient indicated significant $(p<0.05)$ correlations between CBI and PTGI $(r=0.485, \mathrm{p}<0.001)$, and also between CBI and PCL-5 ( $r=0.355, \mathrm{p}<0.001)$. 
Table 1 - Descriptive variables of the sample and mean and SD of additional measures applied in the study

\begin{tabular}{|c|c|}
\hline Variable & $\%$ or mean (SD) \\
\hline \multicolumn{2}{|l|}{ Gender } \\
\hline Female & 65.7 \\
\hline Male & 34.3 \\
\hline Age $(18-45$ years old $)$ & $23.76(6.52)$ \\
\hline \multicolumn{2}{|l|}{ Marital status } \\
\hline Single & 86.6 \\
\hline Married/Common-law marriage & 10.9 \\
\hline Separated/Divorced & 2.5 \\
\hline \multicolumn{2}{|l|}{ Field of study/work } \\
\hline Health & 23.8 \\
\hline Human sciences & 20.5 \\
\hline Exact sciences & 11.3 \\
\hline Not informed & 44.4 \\
\hline \multicolumn{2}{|l|}{ Occupational status } \\
\hline Student & 79 \\
\hline Full-time employee & 12.9 \\
\hline Independent/self-employed & 5.7 \\
\hline Informal employment & 2.4 \\
\hline \multicolumn{2}{|l|}{ Social class* } \\
\hline A & 21 \\
\hline B & 42 \\
\hline C & 26 \\
\hline $\mathrm{D}$ and $\mathrm{E}$ & 11 \\
\hline PCL-5 & $16.77(12.78)$ \\
\hline PTGI & $55.54(21.98)$ \\
\hline
\end{tabular}

\section{Discussion}

This is the first validation study of the Brazilian Portuguese version of the CBI and, according to database searches, the first analysis of the psychometric properties of the CBI in a language other than English. Adequate
Table 3 - Factor loadings of CBI items

\begin{tabular}{|c|c|c|}
\hline \multicolumn{2}{|c|}{ Item } & \multirow{2}{*}{$\begin{array}{c}\begin{array}{c}\text { Factor } \\
\text { loading }\end{array} \\
0.564\end{array}$} \\
\hline 1. & $\begin{array}{l}\text { Because of the event, I seriously examined the } \\
\text { degree to which I believe things that happen to } \\
\text { people are fair. }\end{array}$ & \\
\hline 2. & $\begin{array}{l}\text { Because of the event, I seriously examined the } \\
\text { degree to which I believe things that happen to } \\
\text { people are controllable. }\end{array}$ & 0.598 \\
\hline 3. & $\begin{array}{l}\text { Because of the event, I seriously examined my } \\
\text { assumptions concerning why other people think } \\
\text { and behave the way that they do. }\end{array}$ & 0.556 \\
\hline & $\begin{array}{l}\text { Because of the event, I seriously examined } \\
\text { my beliefs about my relationships with other } \\
\text { people. }\end{array}$ & 0.701 \\
\hline 5. & $\begin{array}{l}\text { Because of the event, I seriously examined my } \\
\text { beliefs about my own abilities, strengths and } \\
\text { weaknesses. }\end{array}$ & 0.685 \\
\hline 6. & $\begin{array}{l}\text { Because of the event, I seriously examined my } \\
\text { beliefs about my expectations for my future. }\end{array}$ & 0.720 \\
\hline 7. & $\begin{array}{l}\text { Because of the event, I seriously examined my } \\
\text { beliefs about the meaning of my life. }\end{array}$ & 0.747 \\
\hline 8. & $\begin{array}{l}\text { Because of the event, I seriously examined my } \\
\text { spiritual or religious beliefs. }\end{array}$ & 0.525 \\
\hline & $\begin{array}{l}\text { Because of the event, I seriously examined } \\
\text { my beliefs about my own value or worth as a } \\
\text { person. }\end{array}$ & 0.735 \\
\hline
\end{tabular}

Table 2 - Inter-item and item-total score correlations from CBI

\begin{tabular}{|c|c|c|c|c|c|c|c|c|c|c|}
\hline & CBI1 & CBI2 & CBI3 & CBI4 & CBI5 & CBI6 & CBI7 & CBI8 & CBI9 & Item-total \\
\hline CBI1 & - & 0.499 & 0.427 & 0.280 & 0.211 & 0.191 & 0.317 & 0.236 & 0.307 & $p=0.000$ \\
\hline CBI2 & & - & 0.376 & 0.376 & 0.273 & 0.276 & 0.303 & 0.238 & 0.303 & $p=0.000$ \\
\hline CBI3 & & & - & 0.406 & 0.206 & 0.268 & 0.254 & 0.138 & 0.339 & $p=0.000$ \\
\hline CBI4 & & & & - & 0.431 & 0.472 & 0.445 & 0.227 & 0.400 & $p=0.000$ \\
\hline CBI5 & & & & & - & 0.606 & 0.414 & 0.265 & 0.487 & $p=0.000$ \\
\hline CBI6 & & & & & & - & 0.549 & 0.251 & 0.453 & $p=0.000$ \\
\hline CBI7 & & & & & & & - & 0.444 & 0.536 & $p=0.000$ \\
\hline CBI8 & & & & & & & & - & 0.384 & $p=0.000$ \\
\hline CBI9 & & & & & & & & & - & $p=0.000$ \\
\hline M & & & & & & & & & & 24.72 \\
\hline SD & & & & & & & & & & 10.07 \\
\hline Cronbach's a & & & & & & & & & & 0.83 \\
\hline
\end{tabular}


internal consistency was found for the global scale, with Cronbach's a $=0.83$, similar to the one found in the normative study also involving a university population (a $=0.82) \cdot{ }^{21}$ Exploratory factor analysis was conducted in order to assess construct validity of the scale. The principal component analysis showed a single factor solution and a variance explanation value $(42.63 \%)$ similar to that of the normative study. ${ }^{21}$ Results of the statistical analysis did not lead to the removal of any item, given that all items showed satisfactory factor loadings for inclusion in the single factor model. Thus, there is no qualitative or quantitative reason to consider a model with more than one factor to quantify the shaking of an individual's beliefs following the experience of a traumatic event the main object of the CBI.

Convergent validity was investigated through correlations between the CBI and other instruments, namely: PTGI, which assesses posttraumatic growth; and PCL-5, which assesses posttraumatic symptoms. As in the normative original study, significant correlations were found between CBI and posttraumatic growth measures with greater intensity, and between CBI and posttraumatic symptoms with less intensity. ${ }^{21}$ Associations between these variables were also found in other studies conducted with American student populations. ${ }^{14,22}$ Longitudinal studies are necessary to effectively investigate how such interactions occur.

In the normative original study, the CBI was the only instrument predicting posttraumatic growth, while scales of well-being, life satisfaction and posttraumatic symptoms did not achieve the same effect. ${ }^{21}$ Thus, it is evidently important for individuals to comprehend events as sufficient challenges to their beliefs, so that the processing of the experience may lead to posttraumatic growth. ${ }^{21}$ The CBI is a novel instrument in the literature, quantifying the intensity of such challenges. The Brazilian Portuguese version of the instrument allows studies in a different cultural context to provide further evidence, leading to a better understanding of the posttraumatic growth phenomenon.

Limitations of this study include, first and foremost, the fact that the sample was limited to students from a single university. The present study is part of a larger research project aimed to explore the posttraumatic growth phenomenon in the Brazilian context. ${ }^{32}$ In order to obtain a larger sample that would allow many exploratory studies on this topic, this type of population was chosen in the larger project. However, conducting research in this context can generate bias, since it is a sample that represents higher economic status compared to other groups in the country. Another important limitation was that fact that the sample not clinical, with a limited number of participants scoring above clinical thresholds in the concurrent measures applied. Future studies investigating the psychometric properties of the CBI should focus on clinical populations with different levels of education. Furthermore, certain psychometric qualities were not examined, such as divergent validity, confirmatory factor analysis, testretest, among others. Again, this is because this study is part of a larger project, and therefore it was not possible to apply all instruments that would allow for a more robust analysis at this moment. Additional analyses might benefit from a longitudinal design. However, despite these limitations, consistent evidence was obtained about construct validity, indicating adequacy of the psychometric properties of the CBI. This confers validity to the Brazilian version of the scale as a useful tool for the psychological assessment of trauma victims, leading to a better knowledge about the posttraumatic growth phenomenon.

\section{Disclosure}

No conflicts of interest declared concerning the publication of this article.

\section{References}

1. Breslau N. The epidemiology of trauma, PTSD, and other posttrauma disorders. Trauma Violence Abuse. 2009;10:198210.

2. American Psychiatric Association. Diagnostic and Statistical Manual of Mental Disorders, Fifth Edition (DSM-5). Arlington: American Psychiatric Publishing; 2013.

3. Ribeiro WS, de Jesus Mari J, Quintana MI, Dewey ME, EvansLacko S, Vilete LMP, et al. The impact of epidemic violence on the prevalence of psychiatric disorders in Sao Paulo and Rio de Janeiro, Brazil. PLoS One. 2013;8:e63545.

4. Bonanno GA. Loss, trauma, and human resilience: have we underestimated the human capacity to thrive after extremely aversive events? Am Psychol. 2004;59:20-8.

5. Bonanno GA, Galea S, Bucciarelli A, Vlahov D. Psychological resilience after disaster: New York city in the aftermath of the September 11th terrorist attack. Psychol Sci. 2006;17:181-6.

6. Calhoun LG, Tedeschi RG. Authors' response: The foundations of posttraumatic growth: new considerations. Psychol Inq. 2004; 15:93-102.

7. Tedeschi RG, Calhoun LG. The Posttraumatic Growth Inventory: measuring the positive legacy of trauma. J Trauma Stress. 1996;9:455-71.

8. Easton SD, Coohey C, Rhodes AM, Moorthy MV. Posttraumatic growth among men with histories of child sexual abuse. Child Maltreat. 2013;18:211-20.

9. Hungerbuehler I, Vollrath ME, Landolt MA. Posttraumatic growth in mothers and fathers of children with severe illnesses. J Health Psychol. 2011;16:1259-67.

10. Sawyer A, Ayers S, Field AP. Posttraumatic growth and adjustment among individuals with cancer or HIV/AIDS: a meta-analysis. Clin Psychol Rev. 2010;30:436-47.

11. Thombre A, Sherman AC, Simonton S. Posttraumatic growth among cancer patients in India. J Behav Med. 2010;33:15-23.

12. Zwahlen D, Hagenbuch N, Carley MI, Jenewein J, Buchi S Posttraumatic growth in cancer patients and partners -- effects of role, gender and the dyad on couples' posttraumatic growth experience. Psychooncology. 2010;19:12-20. 
13. Bensimon M. Elaboration on the association between trauma, PTSD and posttraumatic growth: the role of trait resilience. Pers Individ Dif. 2012;52:782-7.

14. Hobfoll SE, Palmieri PA, Johnson RJ, Canetti-Nisim D, Hall BJ, Galea S. Trajectories of resilience, resistance, and distress during ongoing terrorism: the case of Jews and Arabs in Israel. J Consult Clin Psychol. 2009;77:138.

15. Levine SZ, Laufer A, Stein E, Hamama Raz Y, Solomon Z. Examining the relationship between resilience and posttraumatic growth. J Trauma Stress. 2009;22:282-6.

16. Groleau JM, Calhoun LG, Cann A, Tedeschi RG. The role of centrality of events in posttraumatic distress and posttraumatic growth. Psychol Trauma. 2013;5:477.

17. Hagenaars MA, Van Minnen A. Posttraumatic growth in exposure therapy for PTSD. J Trauma Stress. 2010;23:504-8.

18. Kleim B, Ehlers A. Evidence for a curvilinear relationship between posttraumatic growth and posttrauma depression and PTSD in assault survivors. J Trauma Stress. 2009;22:45-52.

19. Linley PA, Joseph S. Positive change following trauma and adversity: a review. J Trauma Stress. 2004;17:11-21.

20. Triplett KN, Tedeschi RG, Cann A, Calhoun LG, Reeve CL. Posttraumatic growth, meaning in life, and life satisfaction in response to trauma. Psychol Trauma. 2012;4:400.

21. Cann A, Calhoun LG, Tedeschi RG, Kilmer RP, Gil-Rivas V, Vishnevsky $T$, et al. The Core Beliefs Inventory: a brief measure of disruption in the assumptive world. Anxiety Stress Coping. 2010;23:19-34

22. Lindstrom CM, Cann A, Calhoun LG, Tedeschi RG. The relationship of core belief challenge, rumination, disclosure, and sociocultural elements to posttraumatic growth. Psychol Trauma. 2013;5:50.

23. Foa EB, Ehlers A, Clark DM, Tolin DF, Orsillo SM. The Posttraumatic Cognitions Inventory (PTCI): development and validation. Psychol Assess. 1999;11:303.

24. Sbardelloto G, Schaefer LS, Justo AR, Lobo BDOM, Kristensen $\mathrm{CH}$. Adaptação e validação de conteúdo da versão brasileira do Posttraumatic Cognitions Inventory. Rev Saude Publica. 2013;47:326-34.
25. Park CL, Cohen LH, Murch RL. Assessment and prediction of stress related growth. J Pers. 1996;64:71-105.

26. Vogt DS, Shipherd JC, Resick PA. Posttraumatic Maladaptive Beliefs Scale: evolution of the Personal Beliefs and Reactions Scale. Assessment. 2012;19:308-17.

27. Cann A, Calhoun LG, Tedeschi RG, Triplett KN, Vishnevsky T, Lindstrom CM. Assessing posttraumatic cognitive processes: the Event Related Rumination Inventory. Anxiety Stress Coping. 2011;24:137-56.

28. Taku K, Cann A. Cross-national and religious relationships with posttraumatic growth the role of individual differences and perceptions of the triggering event. J Cross Cult Psychol. 2014;45:601-17.

29. Ramos C, Figueiras L, Lopes M, Leal I, Tedeschi RG. Inventário de Crenças Centrais: estrutura fatorial e propriedades psicométricas na população portuguesa. Psicol Saude Doenças. 2016;17:12031.

30. Hair JF, Black WC, Babin BJ, Anderson RE, Tatham RL. Análise multivariada de dados. 6a ed. Porto Alegre: Bookman; 2009.

31. Associação Brasileira de Empresas de Pesquisa (ABEP). Critério de Classificação Econômica Brasil [web site]. 2015 [cited 2019 Dec]. http://www.abep.org/criterio-brasil

32. Silva TLG, Donat JC, Gauer G, Kristensen CH. Posttraumatic growth measures: translation and adaptation of three selfreport instruments to Brazilian Portuguese. Rev Psiquiatr Clin. 2016;43:47-50.

33. Weathers FW, Marx BP, Friedman MJ, Schnurr PP. Posttraumatic stress disorder in DSM-5: new criteria, new measures, and implications for assessment. Psychol Inj Law. 2014;7:93-107.

\section{Correspondence:}

Christian Haag Kristensen

Pontifícia Universidade Católica do Rio Grande do Sul

Av. Ipiranga, 6681, Prédio 11, Jardim Botânico

90619-900 - Porto Alegre, RS - Brazil

Tel.: +55 (51) 33534898

E-mail: christian.kristensen@pucrs.br 